\title{
Rencana Strategis Teknologi Informasi pada PT XYZ dengan Kerangka Kerja Ward dan Peppard
}

\author{
Dicky Pratama ${ }^{1}$, Derry Alamsyah ${ }^{2}$ \\ Sistem Informasi ${ }^{1}$, Teknik Informatika ${ }^{2}$, STMIK GI MDP, Jl. Rajawali No 14 Palembang \\ Telp: (0711) 376400 \\ dqpratama@mdp.ac.id ${ }^{1}$, derry@mdp.ac.id ${ }^{2}$
}

\begin{abstract}
Information technology is a much-needed asset in today's modern era. Not only as a tool as well as a core resource that should be utilized by organizations and companies. PT XYZ is one company that utilizes information technology to support its business process. Xi $x$ hesitate in the procurement of the next information technology, given the cost that it requires. Companies are afraid of the investments made will be in vain because there is no appropriate information technology strategy to support its business processes. Therefore, it is necessary to make information technology strategy with company business strategy. This study was conducted with the work of Ward and Peppard. Before analyzing information technology strategy with SWOT Model Matrix previously performed internal and external environment analysis with Value Chain and PEST Analysis approach. The result of this research is the upcoming application portfolio which is expected to bring the competing superior company.
\end{abstract}

Keyword: Ward dan Peppard, SWOT, Value Chain, PEST Analysis

\begin{abstract}
Abstrak
Teknologi informasi adalah aset yang sangat dibutuhkan di era modern seperti sekarang ini. Tidak hanya sebagai alat bantu namun juga sebagai sumber daya inti yang harus dimanfaatkan oleh organisasi dan perusahaan. PT XYZ adalah satu perusahaan yang memanfaatkan teknologi informasi untuk mendukung proses bisnisnya. Namun PT XYZ ragu dalam pengadaan teknologi informasi selanjutnya, mengingat biaya yang perlu dikeluarkan dalam mengadakan teknologi informasi sangat mahal. Perusahaan takut investasi yang dilakukan akan sia-sia karena belum adanya strategi teknologi informasi yang tepat untuk mendukung proses bisnisnya. Oleh karena itu perlu dibuat strategi teknologi informasi yang mengacu dengan strategi bisnis perusahaan. Penelitian ini dilakukan dengan kerangka kerja Ward dan Peppard. Sebelum menganalisis strategi teknologi informasi dengan Model SWOT Matriks sebelumnya dilakukan analisis lingkungan internal dan eksternal dengan pendekatan Value Chain dan PEST Analysis. Hasil dari penelitian ini adalah portofolio aplikasi yang akan datang yang diharapkan dapat membawa perusahaan unggul bersaing.
\end{abstract}

Kata kunci: Ward dan Peppard, SWOT, Value Chain, PEST Analysis

\section{PENDAHULUAN}

Teknologi informasi adalah aset yang sangat dibutuhkan di era modern seperti sekarang ini. Tidak hanya sebagai alat bantu namun juga sebagai sumber daya inti yang harus dimanfaatkan oleh organisasi dan perusahaan. Informasi yang dihasilkan dari pemanfaatan teknologi informasi ini juga dituntut untuk selalu up to date, relevan serta ada ketika dibutuhkan dalam proses pengambilan keputusan [8].

Perusahaan XYZ adalah sebuah perusahaan retail yang selama ini memanfaatkan teknologi informasi sebagai kunci kegiatan operasional dalam melayani pelanggan. Kuatnya 
persaingan antar perusahaan sejenis membuat perusahaan berupaya untuk selalu berinovasi dalam memanfaatkan teknologi informasi dan strategi bisnis untuk memenangkan kompetisi tersebut. Top management berharap teknologi informasi yang digunakan dapat bermanfaat serta memberikan nilai yang maksimal dalam mencapai keunggulan kompetitif.

Masalah yang kini dihadapi perusahaan tersebut adalah adanya keraguan dalam pengadaan teknologi informasi, mengingat biaya yang perlu dikeluarkan dalam mengadakan teknologi informasi sangat mahal. Perusahaan takut investasi yang dilakukan akan sia-sia karena belum adanya strategi teknologi informasi yang tepat untuk mendukung proses bisnisnya. Oleh karena itu perlu dibuat strategi teknologi informasi yang mengacu dengan strategi bisnis perusahaan.

\section{LANDASAN TEORI}

\subsection{Perencanaan Strategis Sistem Informasi dan Teknologi Informasi (SI/TI)}

Perencanaan strategis SI/TI merupakan proses identifikasi portofolio aplikasi sistem infomasi berbasis komputer yang akan mendukung organisasi dalam pelaksanaan rencana bisnis dan merealisasikan tujuan bisnisnya [15]. Menurut Cassidy yang dikutip dari Fauzi dan Kusumo perencanaan strategis adalah gambaran jelas bagaimana para pengambil keputusan memandang masa depan dengan menggunakan metode perencanaan formal [7].

\subsection{Value Chain}

Value Chain digunakan sebagai alat untuk mengidentifikasi cara-cara menghasilkan nilai tambah bagi konsumen [13]. Aktifitas utama menggambarkan kegiatan yang dilakukan perusahaan atau organisasi secara berurutan, dimulai dengan mendapatkan bahan baku, mengubah bahan baku tersebut menjadi produk jadi, pengemasan dan pengiriman, menjual dan memasarkan barang tersebut hingga memberikan layanan. Kolaborasi aktifitas utama dengan aktifitas pendukung menentukan nilai dan keuntungan bagi perusahaan.

\subsection{SWOT Matriks}

Matriks SWOT menggambarkan secara jelas bagaimana peluang dan ancaman eksternal yang dihadapi perusahaan dapat disesuaikan dengan kekuatan dan kelemahan yang dimilikinya. Matriks ini dapat menghasilkan empat set kemungkinan altenatif strategis [14]. Hasil analisis dengan menggunakan matriks SWOT menghasilkan strategi SO, WO, ST dan WT. Tabel 1 menggambarkan ke empat strategi tersebut:

Tabel 1. Matriks SWOT

\begin{tabular}{|l|l|l|}
\hline IFAS & Kekuatan (Strength) & Kelemahan (Weakness) \\
\hline Peluang (Opportunity) & $\begin{array}{l}\text { STRATEGI SO } \\
\text { Ciptakan strategi yang } \\
\text { menggunakan kekuatan } \\
\text { untuk memanfaatkan } \\
\text { peluang }\end{array}$ & $\begin{array}{l}\text { STRATEGI WO } \\
\text { Ciptakan strategi yang } \\
\text { meminimalkan kelemahan } \\
\text { untuk memanfaatkan } \\
\text { peluang }\end{array}$ \\
\hline Ancaman (Threats) & $\begin{array}{l}\text { STRATEGI ST } \\
\text { Ciptakan strategi yang } \\
\text { menggunakan kekuatan } \\
\text { untuk mengatasi ancaman }\end{array}$ & $\begin{array}{l}\text { STRATEGI WT } \\
\text { Ciptakan strategi yang } \\
\text { meminimalkan kelemahan } \\
\text { dan menghindari ancaman }\end{array}$ \\
\hline
\end{tabular}

Berikut adalah penjelasan mengenai empat strategi yang lahir setelah dilakukan analisis dengan menggunakan matriks SWOT: 
1. Strategi SO (Strength and Oppurtunity). Strategi ini dibuat berdasarkan jalan pikiran perusahaan, yaitu dengan memanfaatkan seluruh kekuatan untuk merebut dan memanfaatkan peluang sebesar - besarnya.

2. Strategi ST (Strength and Threats). Strategi dalam menggunakan kekuatan yang dimiliki perusahaan untuk mengatasi ancaman.

3. Strategi WO (Weakness and Oppurtunity). Strategi ini diterapkan berdasarkan pemanfaatan peluang yang ada dengan cara meminimalkan kelemahan yang ada.

4. Strategi WT (Weakness and Threats). Strategi ini berdasarkan kegiatan yang bersifat defensif dan berusaha meminimalkan kelemahan yang ada serta menghindari ancaman.

\section{METODOLOGI PENELITIAN}

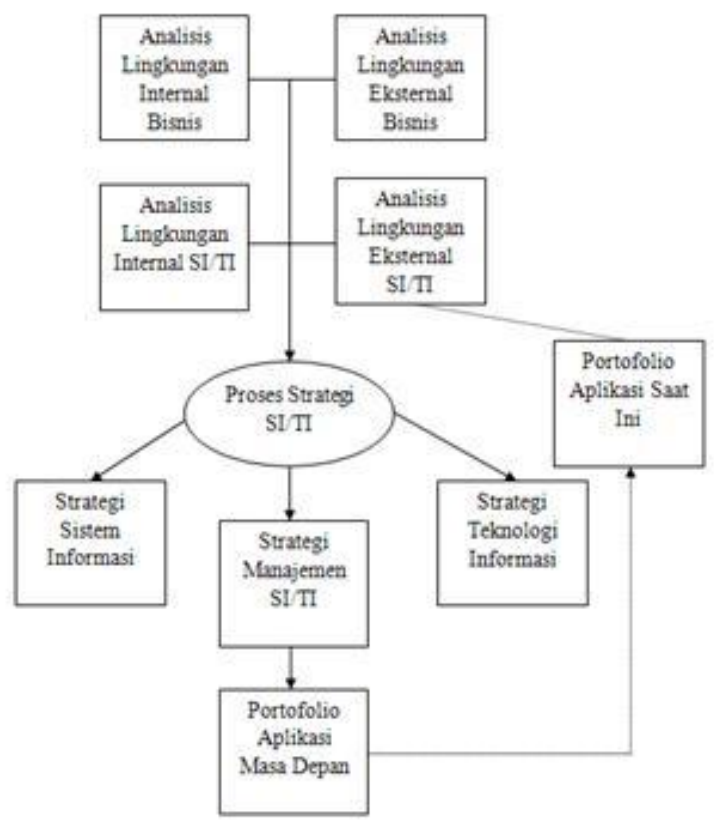

Gambar 1. Model Strategis Sistem Informasi dan Teknologi Informasi (SI/TI)

Gambar 1 menjelaskan tahapan yang dilakukan untuk merumuskan strategi sistem informasi dan strategi teknologi informasi (SI/TI), sebelum menganalisis strategi tersebut maka dilakukan analisis lingkungan internal bisnis dan SI/TI serta analisis lingkungan eksternal bisnis dan SI/TI. Keluaran yang dihasilkan adalah strategi bisnis SI, strategi manajemen SI/TI dan strategi TI. Kerangka fikir pada gambar 1 adalah kerangka yang dikemukakan oleh Ward dan Peppard [15]. Kemudian untuk implementasinya dilakukan dengan model Value Chain, PEST Analysis dan SWOT.

\subsection{Analisis Lingkungan Internal}

Analisis lingkungan internal adalah kegiatan mengidentifikasi sumber daya yang dimiliki perusahaan atau organisasi, baik sumber daya yang berwujud (tangible) atau sumber daya yang tidak berwujud (intangible). Sumber daya yang berwujud contohnya adalah manusia, mesin, uang dan lain sebagainya, sedangkan sumber daya yang tidak berwujud contohnya adalah informasi dan pengetahuan. Analisis lingkungan internal bisnis dilakukan dengan pendekatan model Value Chain. Pendekatan ini dilakukan dengan mengidentifikasi aktivitas utama dan aktivitas pendukung pada perusahaan. 


\subsection{Analisis Lingkungan Eksternal}

Analisis lingkungan eksternal adalah kegiatan mengidentifikasi faktor-faktor yang mempengaruhi perusahaan atau organisasi. Faktor tersebut dapat ditentukan berdasarkan tren teknologi yang sedang marak saat ini, daya saing pesaing, konsumen, pemasok dan lain sebagainya. Analisis ini dilakukan untuk mengidentifikasi apa saja peluang yang dapat dimanfaatkan serta apa saja ancaman yang mungkin menghambat produktifitas perusahaan sehingga diperoleh strategi yang akan direkomendasikan untuk perusahaan agar dapat mengatasi ancaman dan memanfaatkan peluang tersebut.

\subsection{Strategi Sistem Informasi dan Teknologi Informasi (SI/TI)}

Strategi teknologi informasi adalah strategi dalam memanfaatkan sistem informasi (SI) dan teknologi informasi (TI) agar pemanfaatan teknologi informasi dan sistem informasi dapat mengatasi masalah yang ada dan dapat memenuhi kebutuhan pengguna. Perusahaan yang menerapkan strategi teknologi informasi yang tepat dapat meningkatkan efektifitas dan efisiensi dalam proses bisnis bahkan dapat membawa perusahaan mencapai keunggulan kompetitif. Karena perumusan dalam membuat strategi TI mengacu kepada strategi bisnis organisasi.

\section{HASIL DAN PEMBAHASAN}

\subsection{Analisis Lingkungan Internal}

\subsubsection{Analisis Lingkungan Internal Bisnis}

Pendekatan yang dilakukan dalam analisis lingkungan internal bisnis ini adalah dengan memanfaatkan model Value Chain yang dikemukakan oleh Porter (1985). Model ini menitik beratkan kepada aktifitas utama dan aktifitas pendukung pada perusahaan.

\subsubsection{Aktifitas Utama \\ a. Inbound Logistic}

Perusahaan XYZ adalah perusahaan retail alat tulis kantor dan sekolah, perusahaan ini bekerja sama dengan pemasok-pemasok dari dalam kota maupun luar kota. Pemasok mendistribusikan produk mereka ke PT XYZ sesuai dengan pesanan sebelumnya, via jasa ekspedisi maupun tranportasi darat.

\section{b. Operation}

Pencatatan stok dilakukan dengan menggunakan aplikasi pengolahan transaksi. Setiap produk diberikan kode produk sebagai identitas produk.

\section{c. Outbound Logistic}

Setiap order mengurangi stok barang yang ada digudang. Setelah melalui roses pengemasan, produk dikirimkan melalui jasa ekspedisi kepada konsumen yang berada diluar kota dan menggunakan jasa ekspedisi local untuk konsumen yang berada di dalam kota.

\section{d. Marketing and Sales}

Selain memiliki gerai yang buka di jam kerja, perusahaan XYZ ini juga memasarkan produk mereka melalui media sosial, e-commerce pihak ketiga dan website perusahaan. e. Services

Sebagai perusahaan yang telah lama berkecimpung dibidangnya perusahaan ini berusaha untuk mempererat hubungan dengan pelanggan. Layanan yang diberikan kepada pelanggan saat ini adalah request order via telepon dan pengiriman produk ke pelanggan. Penyampaian informasi promosi masih menggunakan brosur yang dicetak serta poster yang di share di jejaring sosial. 


\subsubsection{Aktifitas Pendukung \\ a. Firm Infrastructure}

Infrastruktur yang dimiliki oleh perusahaan yaitu perlengkapan kantor, komputer kasir, mesin cetak dan lain sebagainya. Selain itu perusahaan ini memanfataakan jaringan internet untuk memasarkan produk mereka dan berkomunikasi dengan para mitra.

\section{b. Human Resources Management}

Setiap sumber daya manusia diberikan pelatihan untuk melayani konsumen dan pelatihan penggunaan infrastruktur, perekrutan sumber daya manusia juga dilakukan dengan tes dan interview untuk memilih calon sumber daya manusia yang berkompeten.

c. Technology

Sistem informasi berbasis komputer telah digunakan untuk membantu proses transaksi dengan pelanggan. Informasi yang dihasilkan dalam bentuk laporan digunakan top management sebagai pendukung keputusan.

\section{d. Procurement}

Pengadaan bahan baku untuk packing pengiriman dipesan melalui pemasok, begitu juga untuk pengadaan perlengkapan dan infrastruktur penunjang lainnya.

\subsubsection{Analisis Lingkungan Internal SI/TI}

Analisis lingkungan internal SI/TI dilakukan untuk mengindentifikasi sumber daya sistem informasi dan teknologi yang digunakan perusahaan. Sebelum menjadikan ini sebagai input dalam rekomendasi strategi kedepan maka dilakukan assessment terhadap SI/TI yang digunakan.

\subsubsection{Spesifikasi Hardware}

Perangkat keras (hardware) dilakukan identifikasi karena sering digunakan dalam kegiatan operasional perusahaan. Kinerja dan kecepatan pelayanan kepada pelanggan juga ditentukan oleh perangkat keras yang digunakan. Spesifikasi perangkat keras yang digunakan pada PT XYZ adalah sebagai berikut:

a. Spesifikasi Personal Computer (PC) Direktur dan Manajer

Kesehariaanya direktur manajer PT XYZ menggunakan PC ini untuk berkomunikasi dengan para mitra bisnis. PC ini juga sering kali digunakan untuk menampilkan laporan penjualan dan pembelian produk dan material. Sebagian besar PC yang digunakan oleh direktur dan manajer berspesifikasi sebagai berikut:

Tabel 2. Spesifikasi PC Direktur dan Manajer PT XYZ

\begin{tabular}{|l|l|}
\hline Sistem Operasi & Window 7 \\
\hline Processor & Core i3 2.0 GHz \\
\hline Memory & 2 GB DDR3 \\
\hline Hardisk & $320 \mathrm{~GB}$ \\
\hline
\end{tabular}

Seperti yang dikatakan sebelumnya bahwa spesifikasi berpengaruh terhadap kinerja dan kecepatan dalam mengakses informasi. Maka dapat disimpulkan bahwa spesifikasi PC untuk manajer dan direktur sudah baik.

b. Spesifikasi Personal Computer (PC) Karyawan dan Staff

Tabel 3. Spesifikasi PC Karyawan dan Staff PT XYZ

\begin{tabular}{|l|l|}
\hline Sistem Operasi & Window 7 \\
\hline Processor & Dual Core $2.6 \mathrm{GHz}$ \\
\hline Memory & 2 GB DDR3 \\
\hline Hardisk & $160 \mathrm{~GB}$ \\
\hline
\end{tabular}


Spesifikasi PC staff dan karyawan pada tabel 3 adalah yang selama ini digunakan untuk menjalankan sistem pengolahan transaksi. Kecepatan dan kinerja selain bergantung pada keuletan dari pengguna juga ditentukan dengan komputer yang digunakan. Berdasarkan data yang telah diperoleh pada tabel 3 maka dapat disimpulkan bahwa PC ini dapat dikatakan sudah baik.

\subsubsection{Perangkat Lunak / Software}

Perangkat lunak digunakan untuk mendukung kegiatan operasional seperti mencatat penjualan, membuat laporan dan lain sebagainya. PT XYZ sebelumnya telah memiliki sistem pengolahan transaksi berbasis lokal yang digunakan untuk proses transaksi penjualan, keluaran yang dihasilkan berupa informasi dalam bentuk laporan yang dapat diakses oleh manajer dalam mendukung keputusan. Aplikasi pengolah angka dan pengolah kata dari vendor Microsoft juga sering digunakan untuk menunjang kegiatan bisnis. Selain itu perusahaan ini juga memiliki aplikasi multimedia seperti Adobe Photoshop yang digunakan untuk membuat poster dan design lainnya. Selebihnya adalah sistem operasi yang sebelumnya telah dicantumkan pada tabel 1 dan tabel 2.

\subsection{Analisis Lingkungan Eksternal}

Analisis lingkungan Eksternal dalam penelitian ini dibagi menjadi dua bagian yang pertama adalah analisis lingkungan eksternal bisnis dan selanjutnya adalah analisis lingkungan eksternal SI/TI. Analisis lingkungan eksternal bisnis dilakukan untuk mengidentifikasi peluang yang bisa dimanfaatkan untuk memperoleh keuntungan serta mengidentifikasi ancaman yang mungkin akan menghambat produktifitas perusahaan. Sedangkan analisis lingkungan eksternal SI/TI dilakukan untuk mengidentifikasi tren teknologi yang dapat dimanfaatkan untuk meningkatkan produktifitas perusahaan.

\subsubsection{Analisis Lingkungan Eksternal Bisnis}

Seperti yang telah dikatakan sebelumnya analisis lingkungan eksternal bisnis dilakukan untuk mengidentifikasi apa saja peluang dan ancaman yang akan mungkin muncul. Analisis ini dilakukan dengan menggunakan pendekatan PEST Analysis, faktor peluang dan ancaman diidentifikasi berdasarkan faktor politik, ekonomi, sosial dan teknologi. Berikut analisis lingkungan eksternal bisnis pada PT XYZ:

a. Politik

Seiring dengan diberlakukannya perdagangan bebas dunia pada tahun 2020, Perusahaan bisnis berpeluang memasarkan produknya ke seluruh dunia [6]. Hal ini diperkuat dengan berlakunya Masyarakat Ekonomi ASEAN (MEA) yang dapat dimanfaatkan oleh PT XYZ untuk memasarkan produknya ke Negara lain.

b. Ekonomi

Tingginya tingkat inflasi mengakibatkan meningkatnya biaya produksi perusahaan, penerimaan perusahaan mungkin juga akan tinggi selama periode inflasi tinggi sehingga banyak perusahaan membebankan kepada harga yang lebih tingi sebagai konpensasi dari biaya yang mereka keluarkan sebelumnya. Hal ini merupakan tantangan bagi PT XYZ untuk menyajikan produk dengan harga yang rendah kepada pelanggan dengan cara menekan biaya promosi produk, salah satu cara yang dapat digunakan adalah dengan memanfaatkan e-commerce, SMS Gateway dan email broadcast kepada pelanggan sehingga perusahaan tidak perlu mengeluarkan biaya lebih untuk mengiklankan produk dan pencetakan brosur.

c. Sosial

Semakin banyaknya masyarakat dunia yang terhubung ke jejaring sosial maka semakin besar peluang bagi PT XYZ untuk dapat memasarkan produk di media sosial. Hal ini dilakukan untuk mendekatkan diri kepada pelanggan sehingga dapat memperluas jangkauan pasar. 


\section{d. Teknologi}

Teknologi informasi saat ini telah berkembang pesat, bukan hanya sebagai alat bantu namun telah menjadi kunci dalam kegiatan operasiaonal perusahaan. Sebagian besar pesaing dari PT XYZ telah memanfaatkan sistem pengolahan transaksi dalam melayani transaksi jual beli. Untuk memasarkan produk pesaing juga memanfaatkan e-commerce sehingga mereka dapat bertransaksi secara online.

Tren saat ini yang dapat dimanfaatkan untuk memberikan informasi promosi adalah SMS Gateway. SMS Gateway adalah sebuah gerbang yang menghubungkan antara komputer dengan client melalui media pesan singkat (SMS), Client secara tidak langsung berinteraksi dengan aplikasi atau sistem melalui layanan pesan singkat tersebut [10]. Salah satu produk SMS Gateway yang dapat dimanfaatkan secara open source adalah SMS Gateway Gammu.

\subsubsection{Analisis Lingkungan Eksternal SI/TI}

Analisis lingkungan eksternal SI/TI dilakukan untuk mengidentifikasi tren teknologi yang dapat dimanfaatkan untuk meningkatkan produktifitas perusahaan. Tren teknologi saat ini yang dapat dimanfaatkan untuk mendapatkan pelanggan baru serta mempertahankan pelanggan lama adalah sistem manajemen hubungan pelanggan, dengan sistem informasi tersebut pengguna dapat melakukan customer intimacy dan mempromosikan produk kepada pelanggan. Sistem manajemen hubungan pelanggan berbasis website dapat dikolaborasikan dengan $e$ commerce dan email broadcast sehingga selain dapat memperluas jangkauan pasar PT XYZ juga dapat memberikan informasi promosi.

Untuk mengatasi keterbatasan ruang penyimpanan PT XYZ dapat memanfaatkan teknologi Cloud Storage. Cloud Storage adalah media penyimpanan eksternal dimana file dan berkas disimpan dalam server di internet [3]. Sehingga PT XYZ tidak memerlukan tempat yang besar untuk menyimpan berkas serta mudah dan cepat dalam pengaksesannya.

\subsection{Proses Strategi SI/TI}

Dari hasil analisis lingkungan internal dan eksternal maka ditemukan kekuatan, kelemahan, peluang dan ancaman yang mempengaruhi PT XYZ. Strategi sistem informasi, teknologi informasi dan manajemen informasi dirumuskan berdasarkan hasil analisis yang dilakukan dengan pendekatan model SWOT. Berikut adalah analisis yang dilakukan dengan analisis SWOT tersebut:

Tabel 4. Analisis SWOT

\begin{tabular}{|c|c|c|c|}
\hline & Opportunities & \multicolumn{2}{|l|}{ Threads } \\
\hline & $\begin{array}{ll}\text { 1. } & \text { Meningkatnya jumlah } \\
& \text { mesyarakat yang } \\
& \text { terhubung di internet. } \\
\text { 2. Jaringan pemasaran } & \text { yang luas di } \\
& \text { Indonesia maupun di } \\
& \text { dunia. }\end{array}$ & 1. & $\begin{array}{l}\text { Pesaing yang telah } \\
\text { memiliki reputasi } \\
\text { yang baik. } \\
\text { Teknologi baru yang } \\
\text { digunakan pesaing. }\end{array}$ \\
\hline $\begin{array}{l}\text { Strengths } \\
\text { 1. Pihak manajemen } \\
\text { mendukung } \\
\text { pengembangan } \\
\text { teknologi informasi } \\
\text { 2. Adanya teknologi } \\
\text { hardware yang baik. }\end{array}$ & 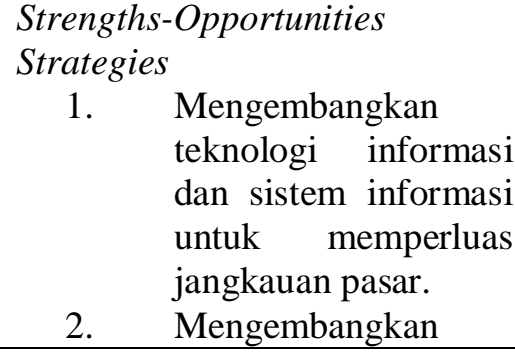 & Strengths & $\begin{array}{l}\text {-Threads Strategies } \\
\text { Meningkatkan } \\
\text { pelayanan dengan } \\
\text { memanfaatkan } \\
\text { teknologi informasi } \\
\text { yang efektif dan } \\
\text { efisien. }\end{array}$ \\
\hline
\end{tabular}




\begin{tabular}{|c|c|c|c|}
\hline & $\begin{array}{l}\text { sistem informasi yang } \\
\text { dapat dikolaborasikan } \\
\text { dengan hardware } \\
\text { yang sudah ada. }\end{array}$ & 2. & $\begin{array}{l}\text { Memanfaatkan } \\
\text { teknologi untuk } \\
\text { meningkatkan daya } \\
\text { saing. }\end{array}$ \\
\hline 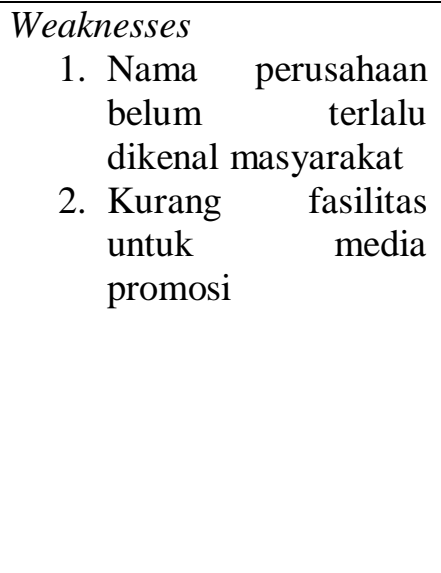 & 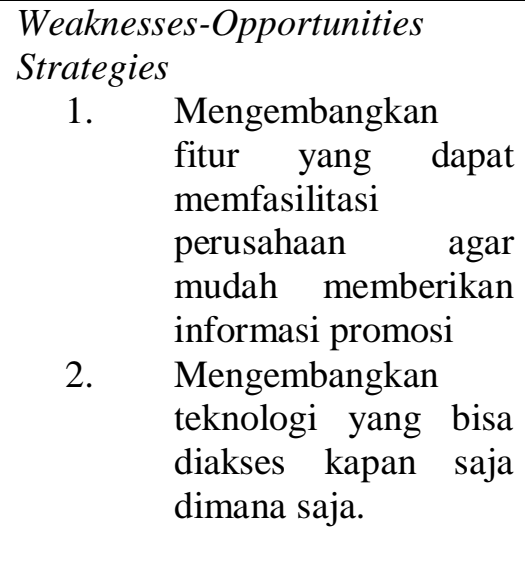 & \multicolumn{2}{|c|}{ 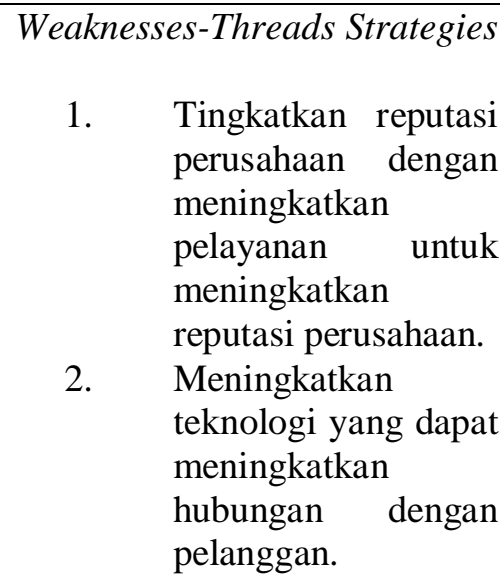 } \\
\hline
\end{tabular}

\subsubsection{Strategi Sistem Informasi Bisnis}

Peran sistem informasi dalam bisnis adalah sebagai pendukung proses bisnis dan operasional, pendukung pengambilan keputusan dan sebagai strategi untuk keunggulan kompetitif [12]. Oleh karena itu diperlukan analisis yang tepat agar investasi yang dilakukan perusahaan dalam pengadaan sistem informasi [11].

Berdasarkan hasil analisis dengan memanfaatkan model SWOT pada tabel 4 maka diperoleh strategi Strengths-Opportunities (SO), Weaknesses-Opportunities (WO), StrengthsThreads Strategies (ST), Weaknesses-Threads Strategies (WT) yang kemudian akan diturunkan menjadi strategi sistem informasi bisnis. Pendekatan yang dilakukan untuk identifikasi strategi sistem informasi bisnis dilakukan dengan memanfaatkan model Critical Success Factors (CSF). Analisis strategi sistem informasi bisnis tersebut dapat dilihat pada tabel 5 berikut:

Tabel 5. Critical Success Factors (CSF)

\begin{tabular}{|c|c|c|c|}
\hline & $C S F$ & Key Decision & $\begin{array}{l}\text { Kebutuhan Sistem } \\
\text { Informasi }\end{array}$ \\
\hline SO & $\begin{array}{l}\text { 1. Mengembangkan } \\
\text { teknologi informasi dan } \\
\text { sistem informasi untuk } \\
\text { memperluas jangkauan } \\
\text { pasar. } \\
\text { 2. Mengembangkan sistem } \\
\text { informasi yang dapat } \\
\text { dikolaborasikan dengan } \\
\text { hardware yang sudah } \\
\text { ada. }\end{array}$ & $\begin{array}{l}\text { 1. Pengembangan dapat } \\
\text { dilakukan dengan } \\
\text { menggunakan jasa } \\
\text { software developer yang } \\
\text { disesuaikan dengan biaya } \\
\text { yang dikeluarkan serta } \\
\text { manfaat yang diperoleh. } \\
\text { 2. Pengembangan sistem } \\
\text { yang disesuaikan dengan } \\
\text { spesifikasi hardware yang } \\
\text { sudah ada sehingga tidak } \\
\text { memerlukan biaya } \\
\text { tambahan dalam } \\
\text { pengadaan hardware. }\end{array}$ & $\begin{array}{ll}\text { 1. } & \text { e-Commerce } \\
\text { 2. } & \text { Customer } \\
& \text { Relationship } \\
\text { Management } \\
\text { System }\end{array}$ \\
\hline ST & 1. Meningkatkan pelayanan & 1. Mengembangkan toko & 1. e-Commerce \\
\hline
\end{tabular}




\begin{tabular}{|c|c|c|c|}
\hline & $\begin{array}{l}\text { dengan memanfaatkan } \\
\text { teknologi informasi yang } \\
\text { efektif dan efisien. } \\
\text { 2. Memanfaatkan teknologi } \\
\text { untuk meningkatkan daya } \\
\text { saing. }\end{array}$ & $\begin{array}{l}\text { online yang mencakup } \\
\text { katalog elektronik yang } \\
\text { interaktif. } \\
\text { 2. Mengembangkan sistem } \\
\text { manajemen hubungan } \\
\text { pelanggan yang dapat } \\
\text { memfasilitasi customer } \\
\text { retention dan customer } \\
\text { intimacy }\end{array}$ & $\begin{array}{ll}\text { 2. } & \text { Customer } \\
\text { Relationship } \\
\text { Management } \\
\text { System }\end{array}$ \\
\hline WO & $\begin{array}{l}\text { 1. Mengembangkan fitur } \\
\text { yang dapat memfasilitasi } \\
\text { perusahaan agar mudah } \\
\text { memberikan informasi } \\
\text { promosi } \\
\text { 2. Mengembangkan } \\
\text { teknologi yang bisa } \\
\text { diakses kapan saja } \\
\text { dimana saja. }\end{array}$ & $\begin{array}{l}\text { 1. Pengembangan fitur yang } \\
\text { dapat memeberikan } \\
\text { informasi mengenai } \\
\text { promosi seperti produk } \\
\text { terbaru, potongan harga dan } \\
\text { lain sebagainya. } \\
\text { 2. Mengembangkan toko } \\
\text { online yang dapat diakses } \\
\text { kapan saja dimana saja. }\end{array}$ & $\begin{array}{l}\text { 1. } \text { Customer } \\
\text { Relationship } \\
\text { Management } \\
\text { System dengan } \\
\text { fitur SMS Gateway } \\
\text { dan Email } \\
\text { Broadcast } \\
\text { 2. } \\
\text { e-Commerce }\end{array}$ \\
\hline WT & $\begin{array}{l}\text { 1. Tingkatkan reputasi } \\
\text { perusahaan dengan } \\
\text { meningkatkan pelayanan } \\
\text { untuk meningkatkan } \\
\text { reputasi perusahaan. } \\
\text { 2. Meningkatkan teknologi } \\
\text { yang dapat meningkatkan } \\
\text { hubungan dengan } \\
\text { pelanggan. }\end{array}$ & $\begin{array}{l}\text { 1. Meningkatkan kinerja, } \\
\text { kecepatan dan akurasi } \\
\text { dengan mengembangkan } \\
\text { sistem yang otomatis. } \\
\text { 2. Mengembangkan sistem } \\
\text { manajemen hubungan } \\
\text { pelanggan yang dapat } \\
\text { memfasilitasi customer } \\
\text { retention dan customer } \\
\text { intimacy }\end{array}$ & $\begin{array}{l}\text { 1. e-Commerce } \\
\text { 2. Customer } \\
\text { Relationship } \\
\text { Management } \\
\text { System }\end{array}$ \\
\hline
\end{tabular}

\subsubsection{Strategi Manajemen SI/TI}

Strategi manajemen SI/TI dilakukan untuk menganalisis apakah investasi yang akan dilakukan oleh PT XYZ sesuai dengan manfaat dan apakah investasi tersebut dapat menguntungkan. Untuk mencapai keunggulan kompetitif dibutuhkan manajemen strategis yang tepat [4], salah satunya dengan pengelolaan tata kelola teknologi informasi. Analisis ini dilakukan dengan memperkirakan biaya yang dikeluarkan oleh perusahaan untuk pengadaan SI/TI ini. Tabel 6 berikut menunjukkan perkiraan biaya investasi SI/TI.

Tabel 6. Perkiraan Biaya Investasi SI/TI PT XYZ

\begin{tabular}{|c|c|c|c|}
\hline Rekomendasi & Qty & Harga (Rp) & Total (Rp) \\
\hline 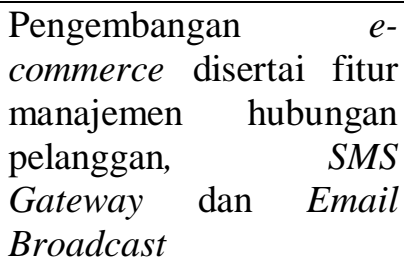 & 1 & 75.000 .000 & 75.000 .000 \\
\hline Biaya Internet Pertahun & 1 & 5.400 .000 & 5.400 .000 \\
\hline $\begin{array}{l}\text { Biaya Sewa Hosting dan } \\
\text { domain pertahun }\end{array}$ & 1 & 1.800 .000 & 1.800 .000 \\
\hline \multicolumn{3}{|c|}{ Total } & 82.200 .000 \\
\hline
\end{tabular}


Berdasarkan data yang peroleh Rp. 75.000 .000 adalah perkiraan biaya untuk mengembangkan sistem manajemen hubungan pelanggan ditambah dengan kelebihan fitur yang direkomedasikan. Biaya internet tersebut merupakan biaya yang dikeluarkan oleh salah satu internet service provider selama satu tahun. Serta biaya sewa hosting dan domain diperlukan untuk mempublikasi sistem berbasis website tersebut selama satu tahun.

4.3.3 Strategi Teknologi Informasi

Strategi teknologi informasi dibuat sebagai acuan dalam pengembangan sistem informasi dan teknologi informasi, serta bagaimana prosedur dalam pengelolaannya [2]. Information Technology Roadmap digunakan untuk menggambarkan target implementasi SI/TI pada PT XYZ, sehingga mudah di monitoring dan evaluasi kedepannya [1]. Berikut adalah IT Roadmap pada PT XYZ

Tabel 7. IT Roadmap pada PT XYZ

\begin{tabular}{|c|c|c|c|c|c|c|c|c|c|c|c|c|c|}
\hline No & Kegiatan & \multicolumn{4}{|c|}{2018} & \multicolumn{4}{|c|}{2019} & \multicolumn{4}{|c|}{2020} \\
\hline & & $\begin{array}{l}\mathrm{Q} \\
1\end{array}$ & $\begin{array}{l}\mathrm{Q} \\
2\end{array}$ & $\begin{array}{l}\mathrm{Q} \\
3\end{array}$ & $\begin{array}{l}\mathrm{Q} \\
4\end{array}$ & $\begin{array}{l}\mathrm{Q} \\
1\end{array}$ & $\begin{array}{l}\mathrm{Q} \\
2\end{array}$ & $\begin{array}{l}\mathrm{Q} \\
3\end{array}$ & $\begin{array}{l}\mathrm{Q} \\
4\end{array}$ & $\begin{array}{l}\mathrm{Q} \\
1\end{array}$ & $\begin{array}{l}\mathrm{Q} \\
2\end{array}$ & $\begin{array}{l}\text { Q } \\
3\end{array}$ & $\begin{array}{l}\mathrm{Q} \\
4\end{array}$ \\
\hline 1 & Pengembangan $e$-commerce & & & & & & & & & & & & \\
\hline 2 & $\begin{array}{l}\text { Penambahan fitur manajemen } \\
\text { hubungan pelanggan }\end{array}$ & & & & & & & & & & & & \\
\hline 3 & $\begin{array}{l}\text { Penambahan fitur email } \\
\text { broadcast }\end{array}$ & & & & & & & & & & & & \\
\hline 4 & $\begin{array}{l}\text { Penambahan fitur SMS } \\
\text { Gateway }\end{array}$ & & & & & & & & & & & & \\
\hline & & & & & & & & & & & & & \\
\hline
\end{tabular}

Tabel 7 menunjukkan tahapan dalam pengembangan sistem yang direkomendasikan untuk PT XYZ. Pengembangan e-commerce untuk ekspansi produk ke seluruh Indonesia dimulai pada quarter ke 2 hingga ke 4 yaitu bulan April hingga bulan Juni tahun 2018. ECommerce mencakup katalog elektronik dan pilihan mekanisme pembayaran serta pemilihan jasa ekspedisi. Penambahan fitur manajemen hubungan pelanggan yang mencakup penyimpanan data pelanggan dengan fitur customer portofolio analysis dan customer retention dilakukan pada quarter pertama hingga quarter ke 2 tahun 2019 (bulan Januari hingga Juni). Penambahan fitur email broadcast dilaksanakan pada quarter 2 hingga quarter 3 pada tahun 2019 (Bulan April hingga bulan September). Penambahan fitur SMS Gateway Gammu dilakukan pada quarter ke 3 hingga quarter ke 4 tahun 2019 (bulan Juli hingga Desember).

Pengembangan sistem informasi dan teknologi informasi ini harus dilakukan monitoring dan evaluasi oleh manajemen puncak. Selain itu perencanaan strategis SI/TI ini membutuhkan dukungan dari manajemen puncak. Karena didalam pembuatan perencanaan bisnis dan strategis sistem dan teknologi informasi tidak bisa dikerjakan tanpa adanya dukungan dan komitmen dari manajemen level atas [5].

\section{KESIMPULAN}

\subsection{Kesimpulan}

Berdasarkan analisis lingkungan internal, lingkungan eksternal dan analisis strategi maka dapat disimpulkan bahwa:

1. PT XYZ harus mengembangkan teknologi informasi dan sistem informasi untuk memperluas jangkauan pasar. Selain itu PT XYZ juga mengembangkan sistem informasi 
yang dapat dikolaborasikan dengan hardware yang sudah ada. Pengembangan sistem informasi tersebut juga bertujuan untuk meningkatkan pelayanan kepada pelanggan.

2. Berdasarkan analisis yang dilakukan dengan model Critical Success Factor (CSF) pengembangan sistem manajemen hubungan pelanggan diperlukan untuk menjalin hubungan baik kepada pelanggan, memberikan kesempatan lebih besar kepada perusahaan untuk mendapatkan pelanggan baru dan mempertahankan pelanggan lama.

3. Pengembangan sistem manajemen hubungan pelanggan juga difasilitasi dengan fitur email broadcast dan SMS gateway untuk mempermudah perusahaan untuk menyebarkan informasi promosi dan produk terbaru.

\subsection{Saran}

Adapun saran yang direkomendasikan untuk PT XYZ dalam implementasi strategi teknologi informasi ini adalah:

1. Berdayakan staf TI untuk sering update informasi tren teknologi terbaru. Berikan pelatihan dalam melakukan pemeliharaan aset teknologi informasi seperti hardware, software, jaringan, manajemen sumber daya data dan yang lainnya.

2. Rencana strategis teknologi informasi ini harus selalu di review untuk menjaga agar strategi bisnis dan strategi teknologi informasi selalu selaras. Untuk periode assesment selanjutnya dilakukan secara berkala agar teknologi informasi yang dimanfaatkan oleh PT XYZ tidak kalah dari pesaing dan memberikan nilai maksimal bagi perusahaan.

3. Rekomendasi teknologi informasi selanjutnya harus disesuaikan dengan kemampuan perusahaan untuk pengadaannya. Analisis biaya dan manfaat dapat dimanfaatkan untuk menilai apakah investasi yang dilakukan oleh perusahaan sesuai dengan manfaat yang diperoleh.

\section{DAFTAR PUSTAKA}

[1] Anthony, R. N., \& Govindarajan, V. 2014, Management Control Systems: European Edition, McGraw-Hill Higher Education.

[2] Bermejo, P. H., \& Tonelli, A. O. 2012, Implementation of Information Technology (IT) Governance Through IT Strategic Planning, African Journal of Business Management Vol. 6, 79-89.

[3] Buyya, R., Broberg, J., \& Goscinski, A. M. 2011, Cloud Computing: Principles and Paradigms, USA: John Wiley and Sons, Inc.

[4] David, F. R. 2014, Strategic Management: A Competitive Advantage Approach, Concepts (15th Edition), New Jersey, Prentice Hall.

[5] Elisabeth, E. F. 2011, Perencanaan Strategis Sistem Informasi PD. Alom Jaya, http://papers.gunadarma.ac.id/index.php/mmsi/article/vie w/14864.

[6] Elisabeth. 2016, IT Strategic Planning pada UMKM XYZ Tahun 2016 - 2020, Seminar Nasional Teknologi Informasi (SNTI) Universitas Taruma Nagara Jakarta.

[7] Fauzi, I., \& Kusumo, D. S. 2014, Perencanaan Strategis Sistem Informasi Menggunakan Metode Anita Cassidy (Studi Kasus: PT. Medika Antapani), Jurnal Ilmiah Online Telkom. 
[8] Hovelja, T., \& Rožanec, A. 2010, Measuring Strategic Information System Planning Success in Enterprises in Slovenia. Management, Vol. 15 , 25-46.

[9] Laudon. 2015, Management Information Systems: Managing the Digital Firm (14th Edition), New Jersey, Prentice Hall.

[10] Maulana, S. 2015, 5 Proyek Popular SMS Gateway, PT. Elex Media, Jakarta.

[11] O'Brien, J., \& Marakas, G. 2011, Management Information System, McGraw Hill, New York.

[12] O'Brien, M. 2012, Introduction to Information Systems - Loose Leaf, McGraw Hill, New York.

[13] Potter, M. E. 2014, Strategy and Competition: The Porter Collection, Harvard Business Review Press, Boston.

[14] Rangkuti, Freddy. 2006, Analisis SWOT Teknik Membedah Kasus Bisnis, PT. Gramedia Pustaka Utama, Jakarta.

[15] Ward, J. \& Peppard, J. 2002, Strategic Planning for Information System (2nd ed), John Wiley \& Sons. 